\title{
Vascular damage in testicular cancer patients: A study on endothelial activation by bleomycin and cisplatin in vitro
}

\author{
JANINE NUVER, ESTHER C. DE HAAS, MARTINE VAN ZWEEDEN, JOURIK A. GIETEMA and COBY MEIJER
}

\begin{abstract}
Department of Medical Oncology, University of Groningen and University Medical Center Groningen, P.O. Box 30.001, 9700 RB Groningen, The Netherlands
\end{abstract}

Received July 31, 2009; Accepted September 16, 2009

DOI: $10.3892 /$ or_00000630

\begin{abstract}
Following treatment with bleomycin- and cisplatincontaining chemotherapy, testicular cancer patients frequently develop vascular complications, which may result from damage to endothelial cells. Understanding bleomycin- and cisplatininduced endothelial alterations may help to develop strategies to prevent or reduce vascular toxicity. The effects of bleomycin and cisplatin on proliferation and apoptosis of the human dermal microvascular endothelial cell line HMEC-1 were determined. In addition, modulation of drug-induced cytotoxicity by the free radical scavenger amifostine, the low molecular weight heparin dalteparin, the iron-chelator dexrazoxane, the HMG-CoA reductase inhibitor rosuvastatin and the PPAR agonist troglitazone was tested. Furthermore, the effects of bleomycin and cisplatin on endothelial activation measured by the expression of the intercellular adhesion molecule-1 (ICAM-1) and on two main proteins involved in fibrinolysis, tissue-type plasminogen activator (tPA) and plasminogen activator inhibitor type 1 (PAI-1), were measured. Decreased endothelial cell survival induced by bleomycin and cisplatin coincided with the induction of apoptosis. Only troglitazone was able to protect the endothelial cells from both bleomycin- and cisplatin-induced cytotoxicity. At high concentrations, amifostine and dexrazoxane also protected HMEC-1 from drug-induced cytotoxicity. However, due to the required high (toxic) concentrations of both modulators no absolute cell survival benefit could be achieved. Both bleomycin and cisplatin induced up-regulation of ICAM-1, tPA and PAI-1. Summarizing, bleomycin and cisplatin induce alterations in the function of endothelial cells regarding proliferation, inflammation and fibrinolysis in vitro. Strategies aimed at these functions should be developed in order to ameliorate or prevent cytostatic agent-induced vascular damage.
\end{abstract}

Correspondence to: Dr Coby Meijer, Department of Medical Oncology, University Medical Center Groningen, P.O. Box 30.001, 9700 RB Groningen, The Netherlands

E-mail: j.meijer@int.umcg.nl

Key words: endothelial cells, bleomycin, cisplatin, intercellular adhesion molecule-1, tissue-type plasminogen activator, plasminogen activator inhibitor type 1

\section{Introduction}

Testicular germ cell tumors are the most common malignancy in men between 20 and 40 years of age. Standard chemotherapy for disseminated testicular cancer includes bleomycin and cisplatin. Both drugs have proven to be important for treatment efficacy resulting in a cure rate $>80 \%$ (1).

An important drawback of the use of bleomycin and cisplatin is the association with vascular toxicity both during treatment and several years thereafter. Raynaud's phenomenon develops in up to $37 \%$ of germ cell cancer patients during treatment with bleomycin-containing chemotherapy $(2,3)$. Thromboembolic events may occur shortly after the administration of cisplatin (4). In addition, long-term survivors of testicular cancer frequently develop risk factors for cardiovascular disease $(5,6)$. After a median of seven years post chemotherapy, long-term survivors of testicular cancer were found to have micro-albuminuria, inflammation, and a imbalance in the plasma levels of the fibrinolytic proteins tissue-type plasminogen activator (tPA) and plasminogen activator inhibitor type 1 (PAI-1) (7), which indicate endothelial dysfunction. Moreover, an increased risk for cardiovascular events has been reported in patients $>10$ years after treatment (8-10).

So far, research has focused on the mechanisms of antitumor activity of bleomycin and cisplatin $(11,12)$. However, little is known about the mechanisms behind their effects on endothelial cells and blood vessels. Bleomycin and cisplatin may directly damage endothelial cells or indirectly influence endothelial cell functions e.g. inflammation and fibrinolysis (13-16). Knowledge of these alterations may contribute to our understanding how these cytostatic agents cause vascular complications. Furthermore, it may enable the development of drugs that can modulate these alterations with the ultimate goal to reduce vascular damage and prevent cardiovascular events.

Primary prevention of bleomycin- and cisplatin-induced endothelial alterations may also be attempted. Several drugs are of interest because of their proven activity in clinical studies or because of their promising mode of action. Amifostine protects from chemotherapy-induced damage through its ability to scavenge free radicals (17). Amifostine has been approved for the prevention of cisplatin-induced nephrotoxicity in patients with non-small cell lung cancer and advanced ovarian cancer (18), but may also be able to reduce chemotherapyinduced vascular toxicity. Iron has been described to be involved in free radical mediated damage of both bleomycin 
and cisplatin $(19,20)$. The hydrolysis product of the prodrug dexrazoxane acts as an iron chelator and may protect cells from chemotherapy-induced damage (21). At present, dexrazoxane is only recommended as a protectant against cardiotoxicity in patients who have already received $>300 \mathrm{mg} / \mathrm{m}^{2}$ of doxorubicin (18). Low molecular weight heparins are of interest because of their improved bio-availability and prolonged anti-thrombotic activity over un-fractionated heparin (22). Statins (HMG-CoA reductase inhibitors) show pleiotropic vasculoprotective properties beyond cholesterol lowering $(23,24)$. Thiazolidinediones, a group of peroxisome proliferator-activated receptor (PPAR) agonists such as troglitazone and rosiglitazone, are used clinically to improve insulin sensitivity, but have also been described to have vasculature protecting properties (25).

In the present study, the human dermal micro-vascular endothelial cell line HMEC-1 was used as an in vitro model to investigate the effects of bleomycin and cisplatin on the proliferation, apoptosis and activation of endothelial cells and to test modulation of these effects by several candidate drugs.

\section{Materials and methods}

Chemicals. MCDB-131 medium, L-glutamine, hydrocortisone, and epidermal growth factor (EGF) were obtained from Invitrogen (Merelbeke, Belgium). Fetal calf serum (FCS) was purchased from Bodinco (Alkmaar, The Netherlands) and MTT (3-(4,5-dimethylthiazol-2-yl)-2,5diphenyl-tetrazoliumbromide), trypsin, acridine orange and troglitazone from Sigma-Aldrich (Amsterdam, The Netherlands). Dimethyl sulfoxide (DMSO) was obtained from Merck (Darmstadt, Germany). Bleomycin and cisplatin were obtained from Pharmachemie (Haarlem, The Netherlands), amifostine and WR-1065 from Shering Plough (Maarssen, The Netherlands), dalteparin (Fragmin ${ }^{\circledR}$ ) from Pharmacia (Woerden, The Netherlands) and dexrazoxane from Chiron (Amsterdam, The Netherlands). Rosuvastatin was a kind gift from Astra Zeneca (Zoetermeer, The Netherlands). The monoclonal ICAM-1/CD54 antibody (B-H17 clone) and the isotype-matched control IgG1 antibody (MCG1 clone) were obtained from IQ Products (Groningen, The Netherlands). TintElize t-PA and TintElize PAI-1 kits were purchased from Kordia (Leiden, The Netherlands). Tumor necrosis factor- $\alpha$ $(\mathrm{TNF}-\alpha)$ was obtained from Boehringer Ingelheim (Ingelheim, Germany).

Cell line. The immortalized human dermal micro-vascular endothelial cell line HMEC-1 was a kind gift of Dr F.J. Candall from the Centers for Disease Control and Prevention (Atlanta, GA, USA). HMEC-1 was described to retain its morphologic and functional endothelial cell characteristics during several passages (26). HMEC-1 was grown as a monolayer in MCDB-131 medium supplemented with $10 \%$ FCS, $10 \mathrm{mM} \mathrm{L}$-glutamine, $1 \mu \mathrm{g} / \mathrm{ml}$ hydrocortisone and $10 \mathrm{ng} /$ $\mathrm{ml}$ human EGF. Cells were cultured at $37^{\circ} \mathrm{C}$ in a humidified atmosphere containing $5 \% \mathrm{CO}_{2}$. Experiments were performed between passages 15-30.

Cytotoxicity. The sensitivity of HMEC-1 to bleomycin and cisplatin was tested using the micro-culture tetrazolium assay (MTT assay) (27). Before starting the experiments, the linear relationship of cell number to formazan crystal formation and the exponential growth of cells in 96-wells micro-culture plates were tested. For the experiments, cells were seeded at 10,000 cells per well. After attachment, the cells were incubated with various concentrations of bleomycin or cisplatin in a total volume of $200 \mu 1$ culture medium. After 96-h incubation, $20 \mu \mathrm{l}$ MTT solution $(5 \mathrm{mg} / \mathrm{ml})$ was added to each well for $225 \mathrm{~min}$; then the plates were centrifuged, the supernatant was aspirated, and the formed formazan crystals were dissolved in $200 \mu \mathrm{l}$ DMSO, after which the extinction was read at $520 \mathrm{~nm}$ using a Benchmark Microplate Reader (Bio-Rad, Veenendaal, The Netherlands). The percentage of cell survival was calculated by dividing the mean of the test sample by the mean of the untreated samples. Controls consisted of media without cells (background extinction) and cells incubated with medium without drugs (growth control). When the growth of cells under control conditions in the experiments was $<50 \%$ of the expected growth, the results of the MTT assays were considered invalid. At least three independent valid experiments were performed.

Modulation of cytotoxicity. The MTT assay was also used to test protective effects of amifostine, dalteparin, dexrazoxane, rosuvastatin and troglitazone on bleomycin- and cisplatininduced cytotoxicity. Since HMEC-1 was not previously characterized with respect to its ability to convert amifostine to WR-1065, both the pro-drug and its active metabolite were used in separate experiments. Cells were seeded in 96-wells micro-culture plates. After attachment, the cells were preincubated with various concentrations of the modulators for $30 \mathrm{~min}$. Then, the cells were incubated with various concentrations of bleomycin or cisplatin in the presence of the modulators for $96 \mathrm{~h}$. After incubation, the MTT assay was performed as described above. At least three individual experiments were performed. Protection from bleomycin- and cisplatin-induced cytotoxicity was assessed using a modified calculation of the so-called enhancement ratio (ER) (28). The ER was calculated by dividing the percentage of endothelial cell survival after exposure to the cytostatic agent combined with the modulator, after correction for the modulator-induced cytotoxicity, by the percentage of endothelial cell survival after exposure to the cytostatic agent alone. An ER >1.20 was considered to indicate protection.

Apoptosis. Staining with acridine orange was used to distinguish apoptotic cells from vital cells (29). In the apoptosis experiments, 25,000 cells per well were incubated with 0.3 or $1.5 \mu \mathrm{g} / \mathrm{ml}$ bleomycin [concentration inhibiting cell survival by $50 \%\left(\mathrm{IC}_{50}\right)$ and $5 \times \mathrm{IC}_{50}$, respectively] and 2.6 or $12.9 \mu \mathrm{M}$ cisplatin $\left(\mathrm{IC}_{50}\right.$ and $5 \times \mathrm{IC}_{50}$, respectively) in 96-well microculture plates in a total volume of $200 \mu 1$. Untreated cells served as control. After 24,48 and $72 \mathrm{~h}$ of incubation at $37^{\circ} \mathrm{C}$, acridine orange was added to a final concentration of $5 \mu \mathrm{g} / \mathrm{ml}$ and cells were incubated at $37^{\circ} \mathrm{C}$ for a further $10 \mathrm{~min}$. Thereafter, $125 \mu \mathrm{l}$ of the supernatant was carefully removed before proceeding with cell counting using a fluorescent microscope (Olympus IM, Japan) at $535 \mathrm{~nm}$. The percentage of apoptotic cells was calculated by dividing the amount of apoptotic cells by the total amount of cells. Three independent experiments were performed. 


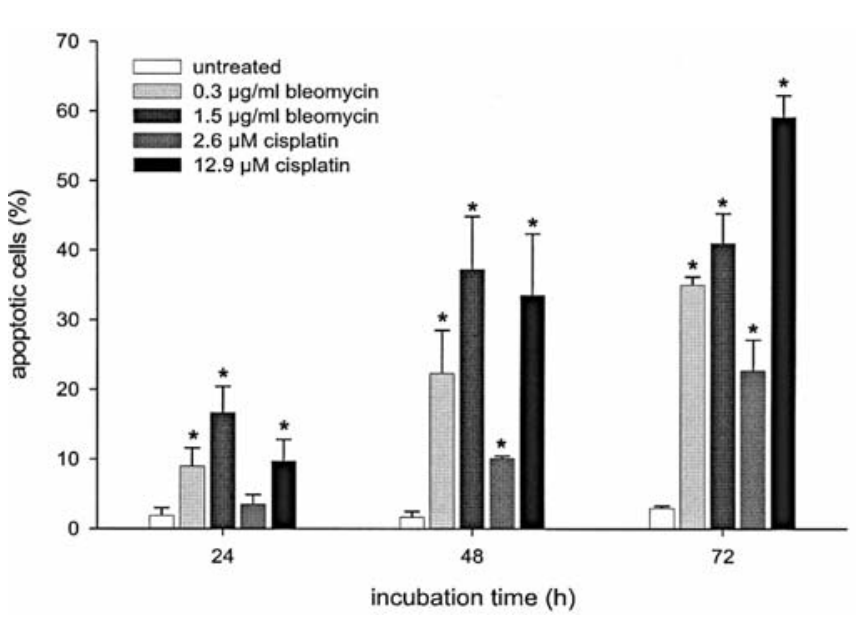

Figure 1. Bleomycin- and cisplatin-induced apoptosis in HMEC-1 after 24, 48 and $72 \mathrm{~h}$ incubation as compared to untreated cells at the corresponding points in time. Values shown denote the mean \pm SDs of three independent experiments; ${ }^{*} \mathrm{P}<0.05$.

ICAM-1 expression determined by direct immunofluorescence and flow cytometry. Cultures of HMEC-1 were left untreated or were exposed to 0.3 or $1.5 \mu \mathrm{g} / \mathrm{ml}$ bleomycin and 2.6 or $12.9 \mu \mathrm{M}$ cisplatin for 24,48 and $72 \mathrm{~h}$. Exposure of cells to $100 \mathrm{ng} / \mathrm{ml} \mathrm{TNF-} \alpha$ was used as a positive control for ICAM-1 expression. After incubation, medium was removed and cells were harvested using trypsin. Then, cells were incubated with either a monoclonal antibody to ICAM-1 or an isotype-matched irrelevant control IgG1 antibody, which were both conjugated with fluorescein isothiocyanate (FITC), after which ICAM-1 expression was analyzed using a fluorescence activated cell sorter (FACS). Ten thousand cells were counted. Results were expressed as mean fluorescence intensity (MFI) of the treated cells divided by the MFI of the untreated cells. At least three individual experiments were performed.

tPA and PAI-1 antigens determined by enzyme-linked immunosorbent assay (ELISA). Cultures of HMEC-1 were incubated with 0.3 or $1.5 \mu \mathrm{g} / \mathrm{ml}$ bleomycin and 2.6 or $12.9 \mu \mathrm{M}$ cisplatin for 24,48 and $72 \mathrm{~h}$. After incubation, the supernatant was removed, centrifuged at $900 \mathrm{rpm}$ and $0^{\circ} \mathrm{C}$ for $10 \mathrm{~min}$ to remove potentially remaining cells and stored at $-20^{\circ} \mathrm{C}$ until analysis. The remaining monolayers of cells were harvested using trypsin and the total amount of cellular protein of the cell lysate was determined according to the method by Bradford (30). tPA and PAI-1 antigens were measured in the supernatant using commercially available ELISA kits according to the manufacturer's instructions. Both ELISAs measure free and complexed antigens. Antigen levels of tPA and PAI-1 in the supernatant were corrected for the total protein concentration of the cell lysate. At least three individual experiments were performed.

Modulation of $T P A$ and PAI-1 antigens by the PPAR agonist troglitazone. Cultures of HMEC-1 were pre-incubated with $50 \mu \mathrm{M}$ of the PPAR agonist troglitazone for $30 \mathrm{~min}$ followed by incubation with $1.5 \mu \mathrm{g} / \mathrm{ml}$ bleomycin or $12.9 \mu \mathrm{M}$ cisplatin [concentrations of drugs inhibiting cell survival by $\sim 90 \%$ $\left.\left(\mathrm{IC}_{90}\right)\right]$ for 24,48 and $72 \mathrm{~h}$. After incubation, the procedure of isolation and determination of tPA and PAI-1 antigens and cellular protein was as described above. Three individual experiments were performed.

Statistics. A paired t-test was used to test differences in apoptosis induction, ICAM-1 expression and PAI-1 and tPA antigen concentrations between untreated cells and cells exposed to bleomycin or cisplatin. All tests were double sided. A P-value $<0.05$ was considered to indicate significance.

\section{Results}

Cytotoxicity. Exposure of endothelial cells to bleomycin and cisplatin for $96 \mathrm{~h}$ yielded $\mathrm{IC}_{50}$ values of $0.3 \mu \mathrm{g} / \mathrm{ml}$ for bleomycin and $2.6 \mu \mathrm{M}$ for cisplatin. The $5 \mathrm{x} \mathrm{IC}_{50}$ values for both cytostatic agents approximated to the $\mathrm{IC}_{90}$ values.

Apoptosis. Fig. 1 shows bleomycin- and cisplatin-induced apoptosis in HMEC-1 after 24, 48 and $72 \mathrm{~h}$ incubation. The percentages of apoptotic cells increased with incubation time for all tested concentrations of cytostatic agents.

Modulation of cytotoxicity. Table I summarizes modulation of cytotoxicity by troglitazone, amifostine and dexrazoxane expressed as ERs. Already at a non-toxic concentration, troglitazone was able to protect the endothelial cells from both bleomycin- and cisplatin-induced cytotoxicity. Absolute protection up to $20 \%$ against both bleomycin- and cisplatininduced cytotoxicity was observed over the range of 20-90\% cell kill of both drugs (Fig. 2). At high concentrations only, amifostine [or its active metabolite WR-1065 (data not shown)] and dexrazoxane also protected HMEC-1 from bleomycin-induced cytotoxicity. However, due to the required high (toxic) concentrations of the modulators no absolute cell survival benefit could be reached. Neither amifostine [or its active metabolite WR-1065 (data not shown)] nor dexrazoxane protected HMEC-1 from cisplatin-induced cytotoxicity (ER <1.20; Table I). No effect of dalteparin or rosuvastatin on bleomycin- or cisplatin-induced cytotoxicity was observed [a wide range of concentrations, from non-toxic to toxic, was tested (data not shown)].

ICAM-1 expression. Fig. 3 shows the ICAM-1 expression after exposure of HMEC-1 to bleomycin and cisplatin for 24, 48 and 72 h. ICAM-1 expression was significantly up-regulated after exposure of cells to $1.5 \mu \mathrm{g} / \mathrm{ml}$ bleomycin and $12.9 \mu \mathrm{M}$ cisplatin and also at the lower $\mathrm{IC}_{50}$ value after $72 \mathrm{~h}$ compared to untreated cells. The positive control TNF- $\alpha$ induced a clear up-regulation of ICAM-1 expression, which increased with incubation time [mean ratio \pm standard deviation (SD): 13.7 $\pm 7.0,31.4 \pm 7.3,42.0 \pm 15.8$ at 24,48 and $72 \mathrm{~h}$, respectively].

tPA and PAI-1 antigens. Fig. 4 shows the amounts of tPA and PAI-1 antigens after exposure of HMEC-1 to bleomycin and cisplatin for 24,48 and $72 \mathrm{~h}$. Both bleomycin and cisplatin induced up-regulation of tPA at 48 and $72 \mathrm{~h}$, except for the lower concentration of cisplatin at $48 \mathrm{~h}$. The $\mathrm{IC}_{90}$ concentrations of bleomycin and cisplatin induced upregulation of PAI-1 at 48 and $72 \mathrm{~h}$. At the $\mathrm{IC}_{50}$ concentration, only bleomycin induced PAI-1 at $72 \mathrm{~h}$. 
Table I. Modulation of drug-induced cytotoxicity.

\begin{tabular}{|c|c|c|c|c|c|c|}
\hline & \multicolumn{2}{|c|}{ Troglitazone } & \multicolumn{2}{|c|}{ Amifostine } & \multicolumn{2}{|c|}{ Dexrazoxane } \\
\hline & $25 \mu \mathrm{M}$ & $50 \mu \mathrm{M}$ & $10 \mu \mathrm{M}$ & $25 \mu \mathrm{M}$ & $5 \mu \mathrm{M}$ & $10 \mu \mathrm{M}$ \\
\hline Modulator-induced cytotoxicity & None & $5-10 \%$ & None & $10-15 \%$ & $10 \%$ & $30 \%$ \\
\hline \multicolumn{7}{|l|}{ Bleomycin $(\mu \mathrm{g} / \mathrm{ml})$} \\
\hline 0.0075 & $1.02 \pm 0.05^{\mathrm{a}}$ & $1.04 \pm 0.05$ & $0.95 \pm 0.02$ & $1.09 \pm 0.09$ & $1.05 \pm 0.02$ & $1.06 \pm 0.03$ \\
\hline 0.015 & $1.07 \pm 0.03$ & $1.08 \pm 0.06$ & $1.00 \pm 0.03$ & $1.11 \pm 0.04$ & $1.05 \pm 0.04$ & $1.08 \pm 0.01$ \\
\hline 0.075 & $1.23 \pm 0.04$ & $1.36 \pm 0.02$ & $1.02 \pm 0.04$ & $1.24 \pm 0.09$ & $1.11 \pm 0.03$ & $1.18 \pm 0.04$ \\
\hline 0.75 & $1.43 \pm 0.13$ & $1.75 \pm 0.20$ & $1.03 \pm 0.02$ & $1.33 \pm 0.08$ & $1.20 \pm 0.03$ & $1.42 \pm 0.10$ \\
\hline 7.5 & $1.71 \pm 0.28$ & $2.36 \pm 0.69$ & $1.09 \pm 0.09$ & $1.88 \pm 0.35$ & $1.38 \pm 0.13$ & $1.91 \pm 0.28$ \\
\hline \multicolumn{7}{|l|}{ Cisplatin $(\mu \mathrm{M})$} \\
\hline 0.3 & $1.00 \pm 0.03$ & $0.99 \pm 0.03$ & $1.01 \pm 0.06$ & $0.98 \pm 0.01$ & $1.00 \pm 0.02$ & $1.06 \pm 0.03$ \\
\hline 0.75 & $1.13 \pm 0.03$ & $1.09 \pm 0.03$ & $0.99 \pm 0.03$ & $0.94 \pm 0.01$ & $1.00 \pm 0.03$ & $1.08 \pm 0.03$ \\
\hline 2 & $1.28 \pm 0.04$ & $1.35 \pm 0.01$ & $1.00 \pm 0.06$ & $1.00 \pm 0.05$ & $1.07 \pm 0.05$ & $1.15 \pm 0.10$ \\
\hline 6.5 & $1.53 \pm 0.12$ & $2.01 \pm 0.09$ & $1.00 \pm 0.04$ & $1.07 \pm 0.08$ & $1.12 \pm 0.05$ & $1.24 \pm 0.03$ \\
\hline 15 & $2.13 \pm 0.20$ & $2.94 \pm 0.58$ & $1.08 \pm 0.06$ & $0.98 \pm 0.23$ & $1.11 \pm 0.22$ & $1.16 \pm 0.17$ \\
\hline
\end{tabular}

${ }^{\mathrm{a}} \mathrm{ER}$ (mean $\pm \mathrm{SD}, \mathrm{n} \geq 3$ ). ERs $>1.20$ (bold) were considered to indicate protection.
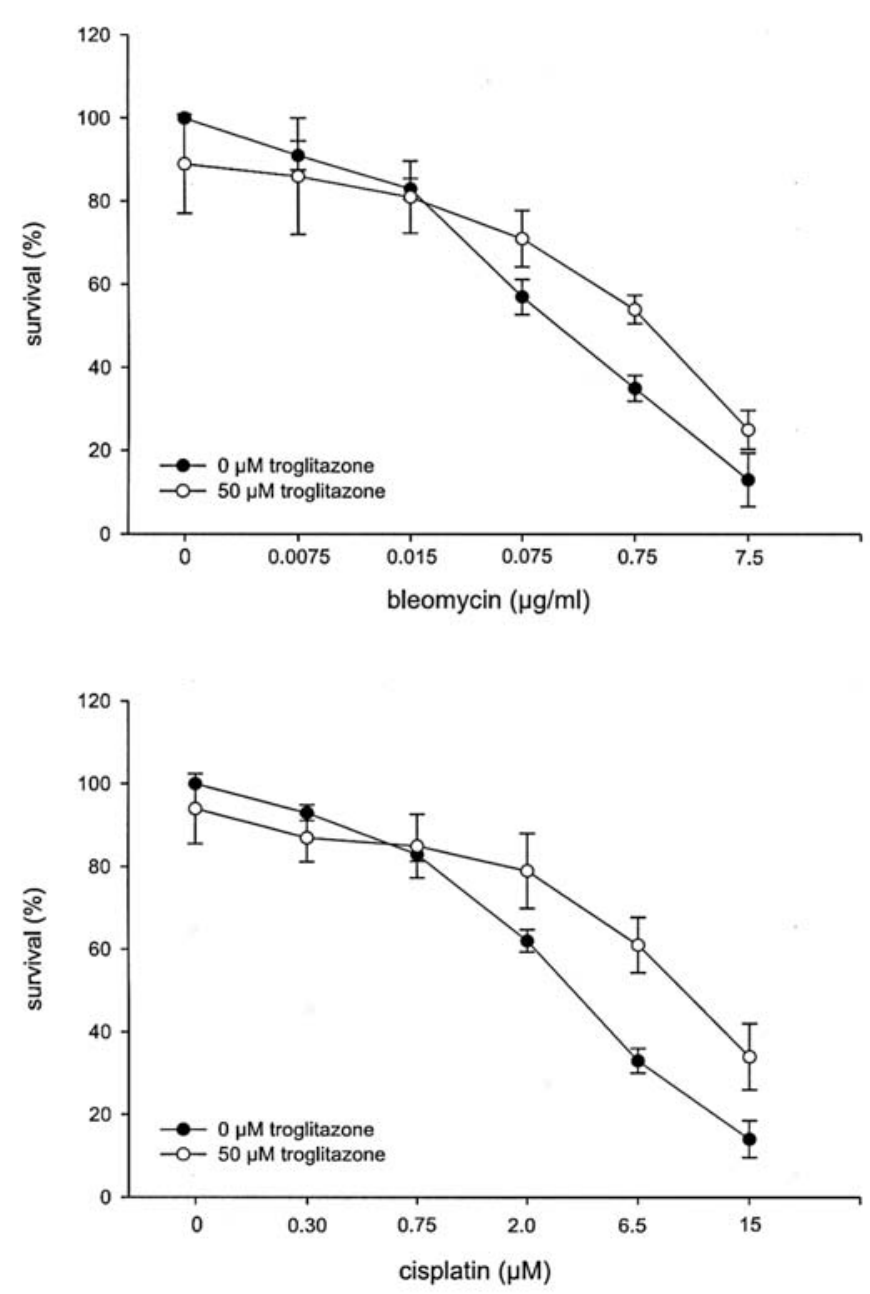

Figure 2. Bleomycin- and cisplatin-induced cytotoxicity in HMEC-1 and its modulation by troglitazone. Values represent the mean \pm SDs of at least three independent experiments. Note: horizontal axis is non-linear.

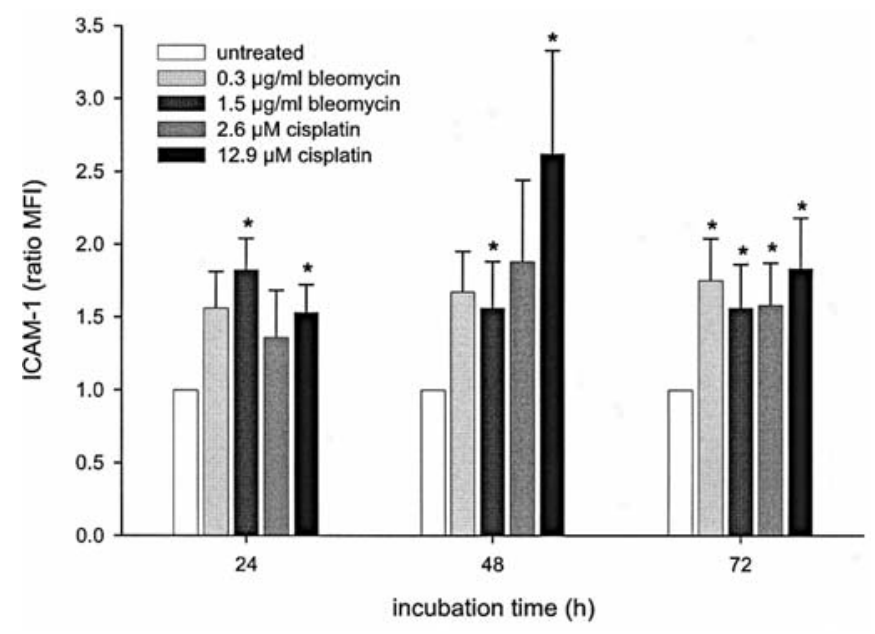

Figure 3. ICAM-1 expression after exposure of HMEC-1 to bleomycin or cisplatin for 24, 48 and $72 \mathrm{~h}$ expressed as ratio MFI (MFI of treated cells divided by MFI of untreated cells). Values represent the mean \pm SDs of at least three independent experiments; ${ }^{*} \mathrm{P}<0.05$.

Modulation of TPA and PAI-1 antigens by the PPAR agonist troglitazone. Neither the constitutive expression nor the bleomycin- or cisplatin-induced expression of tPA and PAI-1 levels were affected by pretreatment of HMEC-1 with troglitazone (data not shown).

\section{Discussion}

The vast majority of patients with disseminated testicular cancer can be cured with bleomycin- and cisplatin-containing chemotherapy. Following this treatment, testicular cancer patients frequently develop vascular complications, which may result from direct or indirect damage to endothelial cells. 

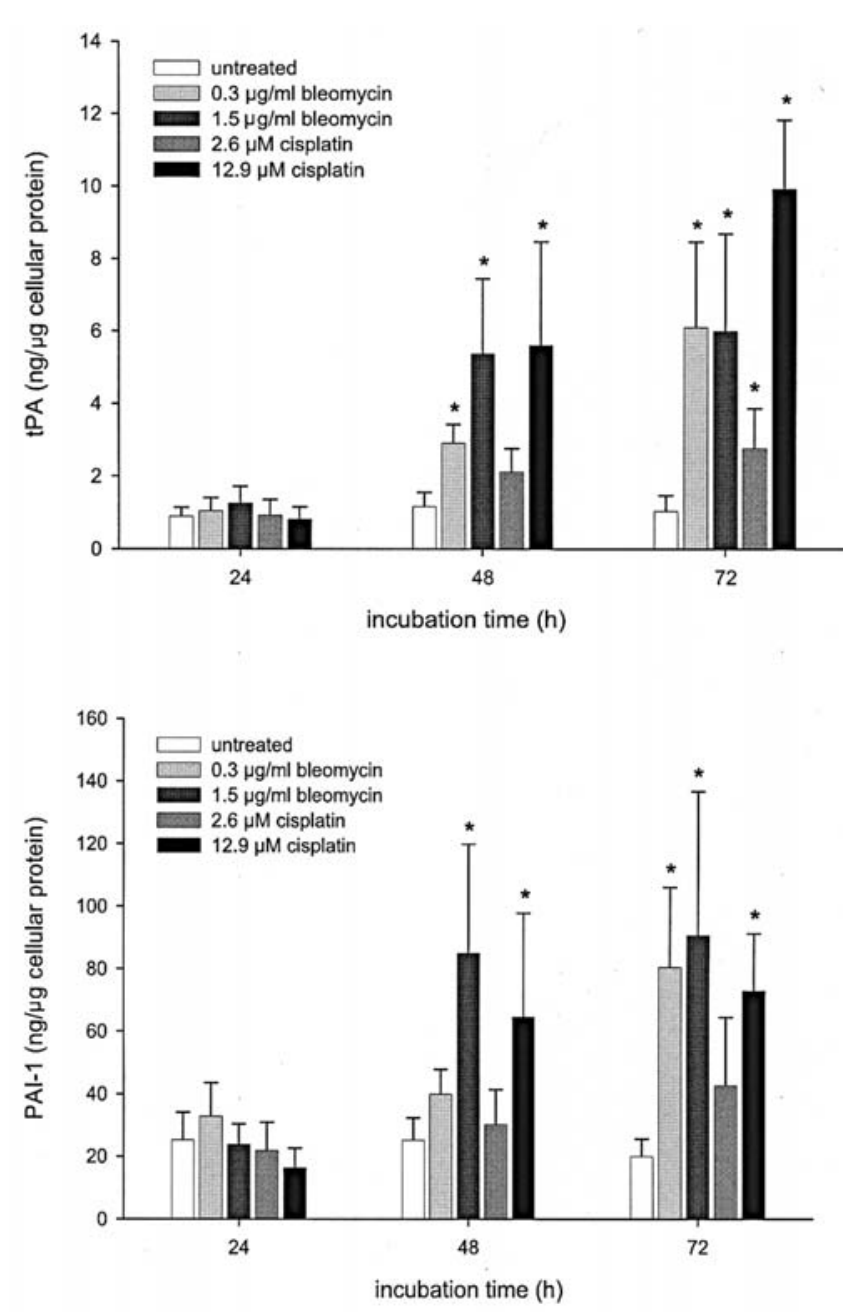

Figure 4. The amounts of tPA (A) and PAI-1 (B) in supernatant per total protein content of the cell lysate after exposure of HMEC-1 cells to bleomycin or cisplatin for 24, 48 and $72 \mathrm{~h}$. Values shown denote the mean \pm SDs of at least three independent experiments; ${ }^{*} \mathrm{P}<0.05$.

We investigated the effects of bleomycin and cisplatin on proliferation, apoptosis, inflammation and fibrinolysis of human endothelial cells in vitro. Both drugs reduced endothelial cell survival, which coincided with the induction of apoptosis. $\mathrm{The}^{\mathrm{IC}_{50}}$ values for both bleomycin and cisplatin in our study fall within the range of plasma concentrations measured in patients after intravenous bolus administration of bleomycine (31) or after administration of $20 \mathrm{mg} / \mathrm{m}^{2}$ cisplatin (32). These results indicate that concentrations of bleomycin and cisplatin reached in patients are sufficient to inflict damage to endothelial cells.

Prevention of bleomycin- and cisplatin-induced cytotoxicity was tested by modulation of drug-induced cytotoxicity by various candidate drugs. Only the PPAR agonist troglitazone was able to truly protect the endothelial cells from both bleomycin- and cisplatin-induced cytotoxicity. Troglitazone belongs to the thiazolidinediones, a novel class of drugs for the treatment of patients with diabetes mellitus type 2 . The family of thiazolidinediones exerts its effects by specifically binding to PPAR $-\gamma$. Like other transcription factors, PPARs regulate the expression of numerous genes (25). Consequently, thiazolidinediones have both PPAR-dependent and -indepen- dent mechanisms of action. Troglitazone has been described among others to inhibit endothelial cell proliferation (33) and fibrinolysis proteins (34) and to possess anti-inflammatory properties (35). The PPAR agonist rosiglitazone has been described to ameliorate cisplatin-induced renal injury in mice (36). Although thiazolidinediones seem to be promising drugs with vasculature protecting properties, care should be taken because of continued uncertainty about safety (37).

Amifostine and dexrazoxane were also able to protect endothelial cells from bleomycin- and cisplatin-induced cytotoxicity in vitro, but only at high concentrations. Since amifostine and dexrazoxane were cytotoxic to HMEC-1 at these concentrations, no or only small increases in absolute cell survival were observed. Interestingly, exposure of HMEC-1 to WR-1065, the active metabolite of amifostine, was previously shown to induce nuclear transcription factor- $\kappa \mathrm{B}$, which regulates the expression of other genes with potentially beneficial effects on endothelial function (38). Therefore, when used in non-cytotoxic concentrations, amifostine may still be of value for the protection of endothelial cells against cytostatic agent-induced damage through its ability to influence gene expression patterns. Although the pleiotropic actions of statins may have potential clinical impact in vascular disease no direct protecting effect of rosuvastatin could be observed on bleomycin- or cisplatin-induced cytotoxicity. Likewise, dalteparin was not able to protect endothelial cells from bleomycin- or cisplatin-induced cytotoxicity in our model. One has to keep in mind that only protection from druginduced cytotoxicity was tested. Therefore, an indirect beneficial effect on endothelial cell function such as inflammation status or fibrinolysis cannot be excluded.

Inflammation is believed to play a role in the early stages of atherosclerosis (39). Activated endothelial cells express intercellular adhesion molecules, such as ICAM-1, which are involved in leukocyte-endothelial cell interactions and the inflammatory response of the vascular wall. In clinical studies, levels of soluble adhesion molecules, including soluble ICAM-1, correlate with various risk factors for cardiovascular disease and predict the development of coronary events (40). In the present study, we found increased expression of ICAM-1 on the surface of endothelial cells in vitro after exposure to bleomycin and cisplatin. Up-regulation of ICAM-1 was also demonstrated in a rat model of bleomycininduced pulmonary fibrosis (41) and in primary human pulmonary micro-vascular endothelial cells (HMVEC-L) after exposure to bleomycine (42). Cisplatin up-regulated ICAM-1 in human umbilical vein endothelial cells (HUVECs) (43) and in a rat model of cisplatin-induced nephrotoxicity renal ICAM-1 mRNA levels were increased after exposure to this drug, while monoclonal anti-ICAM antibodies protected from renal dysfunction following cisplatin administration (44). We previously reported increased levels of the inflammation markers fibrinogen and high-sensitivity $\mathrm{C}$-reactive protein in testicular cancer patients a median of seven years after cisplatin-based chemotherapy (7). No data were available on ICAM-1 levels in these patients. Our finding that ICAM-1 is up-regulated on micro-vascular endothelial cells upon exposure to bleomycin and cisplatin supports the hypothesis that these drugs initiate or promote inflammation and the development of atherosclerosis in testicular cancer patients. 
We previously reported increased concentrations of PAI-1 and tPA in long-term survivors of testicular cancer following bleomycin- and cisplatin-containing chemotherapy (7). Since the increase in PAI-1 was stronger than the increase in tPA, we assumed that fibrinolytic potency was impaired in these patients. In the present study, we found that tPA and PAI-1 antigens are not only constitutively expressed by HMEC-1, but can be up-regulated by bleomycin and cisplatin. It is difficult to ascertain whether the net impact of the changes in tPA and PAI-1 in this in vitro model would impair or favor fibrinolysis. Moreover, we did not investigate the combined effects of bleomycin and cisplatin on PA and PAI-1 levels in HMEC-1, while testicular cancer patients are treated with both agents.

Interestingly, PAI-1 is under control of the PPAR group of transcription factors. The PPAR agonist troglitazone has been described to reduce constitutively expressed or TNF- $\alpha$ induced PAI levels in HUVEC $(34,45)$. Although, troglitazone was able to protect HMEC-1 from both bleomycin- and cisplatin-induced cytotoxicity in our study, no significant effect of troglitazone was observed on constitutively expressed or bleomycin- and cisplatin-induced levels of tPA and PAI-1. Nevertheless, our results show that bleomycin and cisplatin affect the regulation of the balance between pro- and antifibrinolytic proteins by the endothelium, which may contribute to an atherothrombotic state in testicular cancer patients following chemotherapy.

Summarizing, we found decreased cell survival, induction of apoptosis, increased ICAM-1 expression and increased amounts of tPA and PAI-1 in HMEC-1 after exposure to bleomycin and cisplatin in a concentration range that is also be achieved in plasma of testicular cancer patients treated with standard chemotherapy. These endothelial alterations may promote inflammation and atherothrombosis and contribute to cytostatic agent-induced vascular toxicity, a complication which frequently develops in testicular cancer patients following bleomycin- and cisplatin-containing chemotherapy. Except for the PPAR agonist troglitazone, none of the tested drugs was able to modulate the effects of bleomycin and cisplatin on endothelial cells. While this study shows upregulation of a number of selected proteins, the effects of bleomycin and cisplatin on the expression of a wider range of genes and proteins by the endothelium should be investigated in future studies, e.g. by using micro-array. With the increase in numbers of successfully treated cancer patients cured with cytostatic regimens containing bleomycin and/or cisplatin, strategies such as these should be persued to find ways to prevent or reduce treatment-induced cardiovascular damage.

\section{Acknowledgements}

Supported by grant 02-12 from the 'Jan Kornelis de Cock' Foundation.

\section{References}

1. International Germ Cell Consensus Classification: a prognostic factor-based staging system for metastatic germ cell cancers. International Germ Cell Cancer Collaborative Group. J Clin Oncol 15: 594-603, 1997.
2. Vogelzang NJ, Bosl GJ, Johnson K and Kennedy BJ: Raynaud's phenomenon: a common toxicity after combination chemotherapy for testicular cancer. Ann Intern Med 95: 288-292, 1981.

3. Bokemeyer C, Berger CC, Kuczyk MA and Schmoll HJ: Evaluation of long term-toxicity after chemotherapy for testicular cancer. J Clin Oncol 14: 2923-2932, 1996.

4. Weijl NI, Rutten MF, Zwinderman AH, et al: Thromboembolic events during chemotherapy for germ cell cancer: a cohort study and review of the literature. J Clin Oncol 18: 2169-2178, 2000.

5. Raghavan D, Cox K, Childs A, Grygiel J and Sullivan D: Hypercholesterolemia after chemotherapy for testis cancer. J Clin Oncol 10: 1386-1389, 1992.

6. Nord C, Fossa SD and Egeland T: Excessive annual BMI increase after chemotherapy among young survivors of testicular cancer. Br J Cancer 88: 36-41, 2003.

7. Nuver J, Smit AJ, Sleijfer DT, et al: Microalbuminuria, decreased fibrinolysis, and inflammation as early signs of atherosclerosis in long-term survivors of disseminated testicular cancer. Eur J Cancer 40: 701-706, 2004.

8. Meinardi MT, Gietema JA, van der Graaf WT, et al: Cardiovascular morbidity in long-term survivors of metastatic testicular cancer. J Clin Oncol 18: 1725-1732, 2000.

9. Huddart RA, Norman A, Shahidi M, et al: Cardiovascular disease as a long-term complication of treatment for testicular cancer. $\mathbf{J}$ Clin Oncol 21: 1513-1523, 2003.

10. van den Belt-Dusebout AW, Nuver J, de Wit R, et al: Long-term risk of cardiovascular disease in 5-year survivors of testicular cancer. J Clin Oncol 24: 465-475, 2006.

11. Lazo JS: Bleomycin. Cancer Chemother Biol Response Modif 18 : 39-45, 1999.

12. Rabik CA and Dolan ME: Molecular mechamisms of resistance and toxicity associated with platinating agents. Cancer Treat Rev 33: 9-23, 2007.

13. Shi Y, Inoue S, Shinozaki R, Fukue $\mathrm{K}$ and Kougo T: Release of cytokines from human umbilical vein endothelial cells treated with platinum compounds in vitro. Jpn J Cancer 89: 757-767, 1998.

14. Kohn S, Fradis M, Podoshin L, Ben-David J, Zidan J and Robinson E: Endothelial injury of capillaries in the stria vascularis of guinea pigs treated with cisplatin and gentamicin. Ultrastruct Pathol 21: 289-299, 1997.

15. Dirix LY, Libura M, Libura J, Vermeulen PB, de Bruijn EA and van Oosterom AT: In vitro studies with mitomycins and bleomycin on endothelial cells. Anticancer Drugs 8: 859-868, 1997.

16. Phan SH, Gharee-Kermani M, Wolber F and Ryan US: Bleomycin stimulates production of transforming growth factor-beta by rat pulmonary artery endothelial cells. Chest 99: 66S, 1991.

17. Culy CR and Spencer CM: Amifostine: an update on its clinical status as a cytoprotectant in patients with cancer receiving chemotherapy or radiotherapy and its potential therapeutic application in myelodysplastic syndrome. Drugs 61: 641-684, 2001.

18. Schuchter LM, Hensley ML, Meropol NJ and Winer EP: 2002 Update of recommendations for the use of chemotherapy and radiotherapy protectants: clinical practice guidelines of the American Society of Clinical Oncology. J Clin Oncol 20: 2895-2903, 2002.

19. Baliga R, Zhang Z, Baliga M, Ueda N and Shah SV: In vitro and in vivo evidence suggesting a role of iron in cisplatin-induced nephrotoxicity. Kidney Int 53: 394-401, 1998.

20. Weijl NI, Elsendoorn TJ, Moison RM, et al: Non-protein bound iron release during chemotherapy in cancer patients. Clin Sci (Lond) 106: 475-484, 2004.

21. Links $M$ and Lewis C: Chemoprotectants: a review of their clinical pharmacology and therapeutic efficacy. Drugs 57: 293-308, 1999.

22. Burris HA III: Low-molecular-weight heparins in the treatment of cancer-associated thrombosis: a new standard of care? Semin Oncol 33: S3-S16, 2006.

23. Endres M: Statins: potential new indications in inflammatory conditions. Atherosclerosis (Suppl) 7: 31-35, 2006.

24. Krysiak R, Okopien B and Herman Z: Effects of HMG-CoA reductase inhibitors on coagulation and fibrinolysis processes. Drugs 63: 1821-1854, 2003.

25. Blaschke F, Spanheimer R, Khan M and Law RE: Vascular effects of TZD's: new implications. Vascul Pharmacol 45: 3-18, 2006.

26. Ades EW, Candal FJ, Swerlick RA, et al: HMEC-1: establishment of an immortalized human microvascular endothelial cell line. J Invest Dermatol 99: 683-690, 1992. 
27. Meijer C, Timmer A, De Vries EGE, et al: Role of metallothionein in sensitivity of germ cell tumours. Int $\mathrm{J}$ Cancer 85: 777-781, 2000

28. Groen HJ, Sleijfer S, Meijer C, et al: Carboplatin- and cisplatininduced potentiation of moderate-dose radiation cytotoxicity in human lung cancer cell lines. Br J Cancer 72: 1406-1411, 1995.

29. Evans DL and Dive C: Effects of cisplatin on the induction of apoptosis in proliferating hepatoma cells and non-proliferating immature thymocytes. Cancer Res 53: 2133-2139, 1993.

30. Bradford MM: A rapid and sensitive method for the quantitation of microgram quantities of protein utilizing the principle of protein-dye binding. Anal Biochem 72: 248-254, 1976.

31. Alberts DS, Chen HS, Liu R, et al: Bleomycin pharmacokinetics in man I. Intravenous administration. Cancer Chemother Pharmacol 1: 177-181, 1978.

32. Urien S, Brain E, Bugat R, et al: Pharmacokinetics of platinum after oral or intravenous cisplatin: a phase 1 study in 32 adult patients. Cancer Chemother Pharmacol 55: 55-60, 2005.

33. Artwohl M, Furnsinn C, Waldhausl W, et al: Thiazolidinediones inhibit proliferation of microvascular and macrovascular cells by a PPARgamma-independent mechanism. Diabetologia 48: 586-594, 2005

34. Hong HK, Cho YM, Park KH, Lee CT, Lee HK and Park KS: Peroxisome proliferator-activated receptor gamma mediated inhibition of plasminogen activator inhibitor type 1 production and proliferation of human umbilical vein endothelial cells Diabetes Res Clin Pract 62: 1-8, 2003.

35. Arnold R, Neumann M and Konig W: Peroxisome proliferatoractivated receptor gamma agonists inhibit respiratory syncytial virus-induced expression of intercellular adhesion molecule- 1 in human lung epithelial cells. Immunology 121: 71-81, 2007.

36. Lee S, Kim W, Moon SO, et al: Rosiglitazone ameliorates cisplatin-induced renal injury in mice. Nephrol Dial Transplant 21: 2096-2105, 2006.
37. Drazen JM, Morrissey S and Curfman GD: Rosiglitazone continued uncertainty about safety. N Engl J Med 357: 63-64, 2007.

38. Murley JS, Kataoka Y, Hallahan DE, Roberts JC and Grdina DJ: Activation of NFkappaB and MnSOD gene expression by free radical scavengers in human microvascular endothelial cells. Free Radic Biol Med 30: 1426-1439, 2001.

39. Ross R: Atherosclerosis - an inflammatory disease. N Engl J Med 340: 115-126, 1999

40. Blankenberg S, Barbaux S and Tiret L: Adhesion molecules and atherosclerosis. Atherosclerosis 170: 191-203, 2003.

41. Sato N, Suzuki Y, Nishio K, et al: Roles of ICAM-1 for abnormal leukocyte recruitment in the microcirculation of bleomycininduced fibrotic lung injury. Am J Respir Crit Care Med 161: 1681-1688, 2000.

42. Fichter F, Koslowski R, Augstein A, Hempel U, Rohlecke C and Kasper M: Bleomycin induces IL-8 and ICAM-1 expression in microvascular pulmonary endothelial cells. Exp Toxicol Pathol 55: 497-503, 2004.

43. Yu M, Han J, Cui P, et al: Cisplatin up-regulates ICAM-1 expression in endothelial cells via a NF-kappaB dependent pathway. Cancer Sci 99: 391-397, 2008.

44. Kelly KJ, Meehan SM, Colvin RB, Williams WW and Bonventre JV: Protection from toxicant-mediated renal injury in the rat with anti-CD54 antibody. Kidney Int 56: 922-931, 1999.

45. Hamaguchi E, Takamura T, Shimizu A and Nagai Y: Tumor necrosis factor-alpha and troglitazone regulate plasminogen activator inhibitor type 1 production through extra-cellular signal-regulated kinase- and nuclear factor-kappaB-dependent pathways in cultured human umbilical vein endothelial cells. J Pharmacol Exp Ther 307: 987-994, 2003. 